\section{Educação
Por Escrito}

ARTIGO

\section{Editores}

Maria Inês Côrte Vitoria PUCRS, Brasil

Pricila Kohls dos Santos PUCRS, Brasil

\section{Equipe Editorial}

Carla Spagnolo PUCRS, RS, Brasil

Marcelo Oliveira da Silva PUCRS, RS, Brasil

Rosa Maria Rigo

PUCRS, RS, Brasil

\section{ISSN 2179-8435}

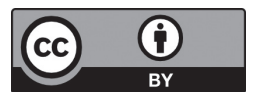

A matéria publicada neste periódico é licenciada sob forma de uma Licença Creative Commons - Atribuição 4.0 Internacional. http://creativecommons.org/licenses/by/4.0/

\section{O papel das Tecnologias de Informação e Comunicação (TICs) na inclusão de alunos com necessidades educacionais especiais no Centro Universitário do Espírito Santo - UNESC}

\author{
The paper of the Technologies of Information and Communication (TICS) \\ on the inclusion of students with educacional special needs \\ in the Centro Universitário do Espírito Santo - UNESC
}

\author{
Renata Domingos ${ }^{\mathrm{a}}$ \\ Georgia Bulian Souza Almeidab \\ Sônia Maria da Costa Barretoc
}

RESUMO: O presente estudo traz como temática central a discussão sobre a inclusão de pessoas com necessidades educacionais especiais no ensino superior, tendo em vista a crescente exigência da formação universitária como fator de desenvolvimento profissional. Tal fato nos leva ao questionamento de quão inclusiva tem sido nossas universidades, sendo necessário pensarmos mecanismos que tornem possível o acesso e a permanência desses alunos no ensino superior. O estudo foi realizado no Centro Universitário do Espírito Santo - UNESC, tendo com foco da pesquisa um aluno com deficiência visual do curso de pedagogia. Para tanto, buscou-se compreender as singularidades da trajetória pessoal e aquelas relativas à escolarização desse sujeito, identificando suas características e suas específicas necessidades no contexto educativo e acadêmico, dando ênfase ao estudo da utilização das tecnologias de informação e comunicação (TICs) como ferramenta facilitadora do processo de ensino/aprendizagem. A metodologia utilizada foi de natureza qualitativa, com inspiração fenomenológica, desenvolvida a partir de entrevista semiestruturada.

Palavras-chave: Educação Superior. Educação Especial. Inclusão de Pessoas com Necessidades Educacionais Especiais. Tecnologias de Informação e Comunicação (TICs).

ABSTRACT: The present study brings like thematic head office the discussion on the inclusion of people with special needs in the upper education, with regard to the increasing exigency of the university training like factor

\footnotetext{
a Doutoranda em Educação pela Universidad Católica de Santa Fé - UCSF. <renatadomin@gmail.com>.

b Mestranda em Gestão Social, Educação e Desenvolvimento Regional na Faculdade Vale do Cricaré. <georgia.ifes@gmail.com>.

c Doutorado em Comunicação e Semiótica pela Pontifícia Universidade Católica de São Paulo.
} 
of professional development. Such fact carries us to the questioning of how inclusive has been ours universities, being necessary think mechanisms that make possible the access and the permanence of these students in the upper education. The study was realized in the Centro Universitário do Espírito Santo - UNESC, having with focus of the investigation a student with visual deficiency of the course of pedagogy. For so much, to quested comprise the singularities of the personal path and those relative to the schooling of this subject, identifying his characteristics and his specific needs in the educational context and academician, giving emphasis to the study of the utilization of the technologies of information and communication (TICs) like tool facilitator of the process of education/learning. The methodology used was of qualitative nature, with inspiration phenomenological, developed from interviews semiestructurad.

Keyword: Upper Education. Special Education. Inclusion of People with Educacional Special Needs. Technologies of Information and Communication (TICS).

E ducação Inclusiva tem sido tema de reflexão para educadores em todos os níveis de ensino, solicitando mudanças textuais, legais, curriculares, avaliativas e de representação desses sujeitos que estão sendo inseridos e das identidades de todos os envolvidos no processo de inclusão.

Entre as principais questões que se apresentam hoje diante da inclusão de alunos com necessidades educacionais especiais, em todos os níveis de ensino, estão a formação docente, os recursos oferecidos a esses alunos e sua representação social perante a sociedade.

A comunidade escolar é desafiada a aprender, respeitar e lidar com a diversidade de seu alunado, adaptar-se as necessidades comuns e também as peculiares de seus alunos, sejam estes com necessidades especiais ou não, oferecendo uma educação de qualidade.

Como pensar nos sujeitos a partir das marcas da diferença, quando na melhor das hipóteses, conseguimos pensálos como sujeitos da diversidade e, portando, plenos de uma cultura? (DUSCHATZKY; SKLIAR, 2000).

Como trazer essa discussão para o contexto das Instituições de Ensino Superior, espaço de formação profissional que deve ter como compromisso pensar formas menos excludentes e discriminatórias.

A Constituição Federal Brasileira de 1988 estabelece que a educação seja um direito de todos (art. 205), embora consistir em sua efetividade tenha se tornado a maior preocupação que repousa sobre esse dispositivo constitucional, especialmente em favor da pessoa com deficiência (BRASIL, 1988).

O direito à educação está incluso no rol dos direitos humanos como se observa em diversos Tratados Internacionais, a Declaração Universal dos Direitos Humanos, adotada em 10 de dezembro de 1948, assegura, em seu artigo 2ํㅡ, o princípio da não-discriminação por motivo de raça, cor, sexo, língua, religião, opiniões, origem 
nacional ou social, riqueza, nascimento ou qualquer outra condição, inclusive a situação política, jurídica ou nível de autonomia do território a que pertençam as pessoas (DECLARAÇÃO DOS DIREITOS HUMANOS, 1948).

Na década de 1990, três documentos tornaram-se referência da inclusão educacional: a Declaração Universal de Educação para Todos, realizada em 1990, em Joimten na Tailândia, a Declaração sobre direito das minorias (dezembro de 1992), enfatizando a necessidade de discriminação em detrimento da proteção de minorias, numa aparente afirmação de que somente indivíduos - e não grupos - deveriam ser tratados em base de igualdade (WUCHER, 2000, p. 95), e a Declaração de Salamanca sobre Princípios, Políticas e Práticas em Educação Especial, produzida pela UNESCO em 1994, na Espanha, propondo que todas as crianças, sempre que possível, deveriam aprender juntas em programas pedagógicos individualizados, independente da condição intelectual, física, emocional e social (BRASIL, 1994).

O art. 3ำ da Declaração Mundial sobre Educação para Todos, traz a necessidade de universalizar o acesso à educação como forma de melhorar a sua qualidade, bem como de tomar medidas efetivas para reduzir as desigualdades. Especificamente quanto às pessoas com necessidades educacionais especiais, rezando que:

As necessidades básicas de aprendizagem das pessoas portadoras de deficiências requerem atenção especial. É preciso tomar medidas que garantam a igualdade de acesso à educação aos portadores de todo e qualquer tipo de deficiência, como parte integrante do sistema educativo. (UNESCO, 1990, p. 4)

Pouco tem se tratado na esfera educacional acerca da inclusão do aluno com necessidades especiais no ensino superior, em pesquisas bibliográficas realizadas, pode-se perceber que as pesquisas sobre a temática em questão são inúmeras, porém elas de certa forma, não acontecem no ensino superior, entretanto, verifica-se que na esfera educacional do ensino superior existe o direito à inclusão e ela aos poucos tem acontecido, com ou sem preparo da IES que receberá tais alunos.

Para Thoma (2006), a inclusão exige rupturas e a busca de alternativas viáveis, pois também é certo que todos têm o direito de alcançar mais altos níveis de escolarização. Por esse motivo a autora defende que uma política precisa ser urgentemente pensada. A investigação sobre as informações e formação dos docentes e sobre resultados alcançados pelas experiências de inclusão já vivenciadas pelas instituições de ensino em geral, devem ser pensadas.

A educação superior, ao lado do ensino fundamental e do ensino médio, constitui-se no pilar do Estado Democrático de Direito, pois sem embargo de dúvidas tem vistas à formação do cidadão que será responsável pelo futuro e pelo desenvolvimento desse sujeito. 
$\mathrm{Na}$ esfera superior de educação é oferecido mais do que as bases do conhecimento, tem-se em vista a formação e disseminação do conhecimento, o desenvolvimento do saber científico, sem perder o foco pela busca, criação e efetivação de melhorias sociais.

Atualmente, as instituições de ensino superior têm se deparado com um fato marcante: a inserção de pessoas com necessidades educacionais especiais. Este acontecimento trouxe à tona algumas deficiências das universidades no atendimento a essa população, dificuldades sentidas tanto por parte dos alunos como dos professores.

Questionamentos quanto suas principais dificuldades, ações a ser pensadas para assegurar a permanência e o aprendizado desses alunos, são questionamentos que não devem ser apenas dos docentes, mas sim de todos os envolvidos nesse processo de inclusão.

Assegurar a todos os acadêmicos um ensino que contribua para sua formação, sejam eles deficientes ou não, que atenda às diferenças individuais, ampliando recursos, serviços que propiciem o desenvolvimento integral, levando em consideração suas necessidades específicas, impostas pela própria condição, é sem dúvida um grande desafio.

Segundo Faria (2005):

[...] deve haver compromisso do Estado e da sociedade no sentido de proporcionar aos 'excluídos' socialmente o acesso ao ensino superior, até em razão de, através desse comportamento, não apenas diminuir as desigualdades existentes no nosso país, mas também visando o desenvolvimento do Brasil [...] (p. 93)

Desafio que pode ser minimizado com a utilização de tecnologias específicas, onde tais recursos possam ampliar as possibilidades de autonomia e melhorar o processo de ensino/ aprendizagem das pessoas com necessidades educacionais especiais.

Igualdade é um dos fundamentos da educação inclusiva. No entanto, igualdade não significa tornar igual, "não é nivelar nem uniformizar o discurso e a prática, mas exatamente o contrário: as diferenças, em vez de inibidas, são valorizadas" (SANTOS; PAULINO, 2006, p. 12). Assim, a educação inclusiva, segundo os autores, busca, como princípio fundamental,

[...] a minimização de todo e qualquer tipo de exclusão em arenas educacionais e, com isso, elevar ao máximo o nível de participação, coletiva e individual, de seus integrantes. Baseadas nestes ideais democráticos, as propostas inclusivas são revolucionárias, pois almejam incondicionalmente, uma estrutura social menos hierarquizada e excludente, tendo como base o argumento de que todos temos o mesmo valor, pelo simples fato de sermos humanos. E que, por isso mesmo, todos precisamos ser considerados e respeitados em nossa maneira subjetiva e única de existir [...] (SANTOS; PAULINO, 2006, p. 12) 
Buscando o aprofundamento do tema ainda pouco explorado que envolve o entrelaçamento destes dois fenômenos Inclusão e Ensino Superior - é que tencionou escolher um pequeno recorte da população com necessidades educacionais especiais e investigar como e se a entrada no ensino superior tem ocasionado melhorias na qualidade de vida e inserção no mercado de trabalho, e ainda, se a utilização das Tecnologias de Informação e Comunicação - TICs no processo de ensino/ aprendizagem dos alunos com necessidades educacionais especiais tem favorecido a inclusão desses alunos não apenas na IES, mas sim na sociedade.

O recorte supracitado refere-se a um aluno do sexo masculino, com deficiência visual, matriculado atualmente no curso superior de Pedagogia do Centro Universitário do Espírito Santo - UNESC. A fonte principal da investigação será o próprio sujeito pesquisado. A metodologia utilizada foi de natureza qualitativa, com inspiração fenomenológica, desenvolvida a partir de entrevista semiestruturada.

Dar voz às suas angústias, motivações, desejos e dificuldades, buscando descobrir, a partir de suas falas, se o ingresso no ensino superior e a utilização das Tecnologias de Informação e Comunicação - TICs têm contribuindo para seu processo de formação no ensino superior.

\section{Necessidades educacionais especiais e as Tecnologias de Informação e Comunicação}

Atualmente, muito está se discutindo sobre a prática docente através do uso das Tecnologias de Informação e Comunicação - TICs, que além de favorecer determinados comportamentos, influencia nos processos de aprendizagem. A utilização devidamente planejada e adequada pode viabilizar e favorecer o desenvolvimento e aprendizado do aluno com necessidade especial, e ainda pode contribuir no seu processo de inclusão no contexto da escola regular.

Conforme diz Mantoan (2011),

[...] para se tornarem inclusivas, acessíveis a todos os seus alunos, as escolas precisam se organizar como sistemas abertos, em função das trocas entre seus elementos e com aqueles que lhe são externos. Os professores precisam dotar as salas de aula e os demais espaços pedagógicos de recursos variados, propiciando atividades flexíveis, abrangentes em seus objetivos e conteúdos, nas quais os alunos se encaixam, segundo seus interesses, inclinações e habilidades [...] (p. 22)

As Tecnologias de Informação e Comunicação - TICs são recursos altamente atrativos, instigantes e estimulantes para que o aprendizado dos alunos aconteça sem traumas, inclusive favorecendo a cooperatividade. 
É necessário propiciar a oportunidade de aprender, interagir, criar, pensar e ter acesso a todas as tecnologias que o auxiliem a superar as barreiras que encontra em razão de sua limitação e valorizando sempre suas potencialidades.

A construção de uma sociedade de plena participação e igualdade tem como um de seus princípios a interação efetiva de todos os cidadãos. Nesta perspectiva é fundamental a construção de políticas de inclusão para o reconhecimento da diferença e para desencadear uma revolução conceitual que conceba uma sociedade em que todos devem participar, com direito de igualdade e de acordo com suas especificidades. (CONFORTO; SANTAROSA, 2002, p. 12).

A prática docente através do uso de Tecnologias da Informação e de Comunicação se apresenta como um desses meios, mostrando a grande funcionalidade do uso do computador pelos alunos com necessidades especiais, acreditando que este recurso auxilia qualquer que seja o grau de necessidade do aluno, até porque é composto de diversas ferramentas, e estas propiciam um trabalho lúdico-pedagógico, desde que mediado por profissionais qualificados.

Valente (1991) coloca que,

O computador significa para o deficiente físico um caderno eletrônico; para o deficiente auditivo, a ponte entre o concreto e o abstrato; para o deficiente visual, o integrador de conhecimento; para o autista, o mediador da interação com a realidade; e, para o deficiente mental, um objeto desafiador de suas capacidades intelectuais. (p. 48)

Não só o computador, mas as diversas mídias existentes podem promover situações de aprendizagem que favoreçam a construção do conhecimento de forma mais atrativa, significativa, participativa e colaborativa para todos os alunos, principalmente os com necessidades especiais.

De forma mais peculiar, as Tecnologias de Informação e Comunicação - TICs podem auxiliar alunos com necessidades especiais a suplantar problemas de mobilidade, limitações físicas ou discriminação social. Em outro argumento, o autor lembra ainda que todas as tecnologias tem influência sobre a estruturação das relações humanas, “o propósito real das TICs é reestruturar as comunicações e as relações humanas" (WARSCHAUER, 2006, p. 279), gerando desenvolvimento sociocognitivo e constituindo uma prática de inclusão digital. 


\section{0 impacto das Tecnologias de Informação e Comunicação - TICs no processo de inclusão de alunos com deficiencia visual no Centro Universitário do Espírito Santo - UNESC: metodologia da pesquisa}

A pesquisa foi de abordagem qualitativa, pois se buscou responder questões que não podem ou não devem ser quantificadas, trabalhando com um universo de significados, motivos, aspirações, crenças, valores e atitudes.

A expressão "pesquisa qualitativa" assume diferentes significados no campo das ciências sociais. Compreende um conjunto de diferentes técnicas interpretativas que visam a descrever e a decodificar os componentes de um sistema complexo de significados. Tem por objetivo traduzir e expressar o sentido dos fenômenos do mundo social; trata-se de diminuir a distância entre indicador e indicado, entre teoria e dados, entre contexto e ação. (MAANEN, 1979a, p. 520)

Nesse tipo de pesquisa, os pesquisadores, ao utilizarem métodos qualitativos estão mais interessados com o processo social do que com a estrutura social; visualizando o contexto e, se possível, ter uma integração empática com o objeto de estudo, implicando melhor compreensão do fenômeno.

De natureza exploratória, por ser necessário um levantamento bibliográfico a cerca do problema a ser estudado, entrevista com pessoas que tiveram (ou tem) experiências práticas com o problema pesquisado e análise de exemplos que estimulem a compreensão.

As reflexões feitas até este ponto do artigo, são fruto do deslocamento do meu olhar em sentido duplo, tanto da realidade global para meu universo local, quanto da experiência que vivi com minha primeira turma de ensino superior.

Bogdan e Biklen (1994, p. 85) colocam: "Frequentemente, a própria biografia pessoal influencia, de forma decisiva, a orientação de um trabalho" (p. 85). O gatilho de interesse para focar na relação entre deficientes visuais, tecnologias e a inclusão desses sujeitos no ensino superior está intimamente ligado à minha história, tornando esta pesquisa uma experiência-piloto.

Um olhar mais aprofundado sobre o percurso escolar do meu primeiro aluno com deficiência visual, o qual carinhosamente chamarei de Alexandre, se entrelaça com o meu e ascende um vasto horizonte de dúvidas, questionamentos, inseguranças e investigações de uma docente, que mesmo sem ser capacitada para lidar com alunos deficientes visuais, precisava aprender a como tirar o melhor desse aluno e ainda dar o meu melhor, fazer com que o processo de ensino aprendizagem acontecesse de maneira tranquila e comum, assim como com os demais alunos da turma.

Ele se desdobrou em um estudo sobre o relacionamento de um aluno com deficiência visual, as tecnologias disponíveis e a aceitação do professor em questão, sobre como usar toda e qualquer tecnologia em favor de ambos. 
Focando nos impactos que a mesma causou em sua trajetória escolar e também profissional. Tal estudo foi de inspiração fenomenológica, pois nele há a valorização da subjetividade, dos discursos e das experiências vividas em sala de aula, focando mais em "compreender do que explicar o fenômeno" (HALL; GARDNER, 1984, p. 82).

$\mathrm{O}$ que se buscou foi o estudo dos modos pelos quais aluno e professor superaram as diferenças, buscando o acesso e a permanência desse aluno no curso Superior de Pedagogia do Centro Universitário do Espírito Santo UNESC e o crescimento profissional do professor envolvido nesse processo.

Fui ao mesmo tempo sujeito e também objeto da pesquisa, devido ao contato quase que diário com o fenômeno estudado, o relacionamento professor, aluno e tecnologias. Indagava, procurava saber, estudava novas tecnologias, aprendia, registrava o que ouvia e o que era feito. Segundo Gil (2010), as pesquisas fenomenológicas em educação, "podem ser interessantes para investigar o cotidiano dos alunos, o relacionamento professor-aluno, as aspirações acadêmicas, o medo do fracasso e da punição e a satisfação dos professores com a profissão" (p. 137).

Tendo em vista que as técnicas mais adequadas para a coleta de dados na pesquisa fenomenológica são as que possibilitam a livre expressão dos participantes, que é essencial tanto para a descrição quanto para a interpretação da experiência vivida, o fato de lecionar as disciplinas de informática e educação em ambientes virtuais por dois semestres seguidos para uma turma que tinha em sua composição alunos com necessidades especiais foi determinante para selecionar o aluno que faria parte do estudo, visto que a metodologia escolhida ajusta-se melhor a problemas que se referem à experiências vividas no dia a dia das pessoas (GIL, 2010).

\subsection{0 início da história}

Alexandre, como será chamado durante o artigo, tem 34 anos e sempre teve o sonho de ser advogado. Em 2008 fez matricula no curso de Direito do UNESC, onde cursou 03 semestres letivos, sempre ficando com algumas dependências, ou seja, não conseguia passar nas disciplinas onde a leitura era o ponto forte.

No ano de 2009, me convidaram para lecionar a disciplina de Metodologia Científica aplicada ao Direito a um aluno, que de acordo com a coordenação, possuía problemas de aprendizagem, achando que era apenas falta de estudo ou algo do tipo, aceitei lecionar por três horas semanais ao aluno. Ao encontrar Alexandre no primeiro dia de aula, percebi que ele era deficiente visual, e eu nunca tinha trabalhado com nenhum aluno com deficiência, e nem tinha especialização no assunto, mas aceitei o desafio e começamos conversar.

O primeiro questionamento veio por parte dele, perguntando como eu poderia dar metodologia científica se ele não tinha acesso ao material de aula. Foi aí que me dei conta de que o problema não era apenas a dificuldade do Alexandre em absorver o conteúdo, mas sim o despreparo do corpo docente em preparar o material para que o mesmo pudesse ter acesso. Foi aí que definitivamente nossos caminhos se cruzaram de vez. 
Vontade para aprender ele tinha de sobra, e eu, muita vontade de ensinar.

Ao contrário do que eu esperava, Alexandre, que nunca tinha utilizado um computador, não foi nada resistente a utilizar as tecnologias, e assim fizemos, começamos com o "DOS-VOX”, sistema que lê e digitaliza o som em português, tendo como limitação o acesso a internet, por não conseguir ler figuras e gráficos.

Como nosso objetivo inicial era trabalhar com textos, utilizamos o DOS-VOX, que além de ser um software gratuito, já é instalado em todas as máquinas da faculdade, e assim todos os dias Alexandre tinha um novo texto para "ler", quem antes não tinha conteúdo, se viu repleto de material, e foi a fundo em todas as leituras. De textos passamos a artigos, depois para reportagens e enfim a livros completos, que também são distribuídos gratuitamente na internet. Logo surgiu a necessidade de utilizarmos a internet como ferramenta de pesquisa, passando assim para outro software, mais potente e que permitia irmos mais longe, optamos assim pelo "JAWS".

O JAWS é um programa de auxílio para deficientes visuais, composto por um sistema de leitura de telas exibidas no computador e sintetizador de voz para reconhecimento de comandos efetuados por parte do usuário. Uma vez instalado, o JAWS facilita o acesso para pessoas com problemas visuais, pois ele literalmente lê o conteúdo exibido na tela do computador para seu usuário. O programa oferece alguns comandos úteis que servem como atalhos para facilitar o uso de programas, edição de documentos e leituras de páginas da internet, além de possibilitar a perfeita utilização do Microsoft Office, Internet Explorer, Windows Live Messenger, Corel Word Perfect, Adobe Acrobat Reader.

Agora, além dos textos trabalhados em sala, Alexandre tinha a sua disposição todo o conteúdo que a internet disponibiliza, como bases de dados, revistas, livros, redes sociais, e-mails, portal universitário, enfim, Alexandre começou em 2009 a ter acesso a tudo o que os demais alunos tinham.

Segundo Assmann (1998), a tecnologia deve apontar para “... a construção de um projeto de sociedade que traga em sua essência uma forma de pensar que permita a existência de vida antes da morte...” (p. 13) para os excluídos, para os com necessidades especiais, para os sujeitos com problemas psíquicos, para os jovens de periferia desprovidos de capital cultural, condicionando uma forma de pensar mais coerente com a teia da vida.

As novas tecnologias corroboram com a mobilidade humana e, ao multiplicar proximidades cognitivas e afetivas, apontam para a heterogeneidade do coletivo, que perfilha e estima a diversidade humana sem qualquer exclusão. São Tecnologias de Informação e Comunicação - TICs que, ao atuarem como objetos catalisadores da inteligência coletiva, tornam-se entidades que propiciam o amparo da diversidade.

As redes digitais, especialmente as ferramentas da Internet, abrem um enorme campo de possibilidades para o lazer, para a formação, para o trabalho e para a vida social, potencializando a inclusão e a valorização da diversidade humana. 
A utilização dos recursos da informática foi extremamente benéfico para Alexandre, sobretudo sua familiarização com a Internet. A rede mundial de computadores ampliou seu círculo social e permitiu a aproximação, mesmo que virtual, com alunos de diversas faculdades e de diversas áreas. Além disso, a quase infinita gama de informações sobre assuntos diversos tornou-se para ele fonte de pesquisa, aprendizagem e troca.

Contribuir, então para o afastamento de Alexandre dos índices de exclusão, possibilitando que a utilização das Tecnologias de Informação e Comunicação - TICs oferecidas pelos computadores do UNESC por ele, trouxe grande satisfação para mim, como professora, e grande evolução para ele.

Incentivar e mostrar que ele era capaz, por si só, de vencer seus desafios foi ponto essencial em sua trajetória de transformação de vida.

\subsection{Um novo olhar sobre a Educação}

Para Alexandre, a utilização das tecnologias que proporcionaram a ele acesso a todo o tipo de material e informação, fez com que olhasse para o curso superior como a possibilidade de abrir novas portas a outros alunos com necessidades especiais, sejam elas físicas ou mentais. Ele decidiu em 2010 passar para o curso de Pedagogia, onde cursou durante dois semestres as disciplinas de informática e educação em ambientes virtuais.

Hoje ele sabe que pode ter acesso a todo o material passado em sala, pode debater de igual para igual com todos os colegas, e é meu atual monitor de informática para outros alunos com deficiência visual.

A utilização das Tecnologias de Informação e Comunicação - TICs fez com que ele acreditasse mais em seu potencial, e também fez com que os demais professores e colegas também acreditassem em seu potencial, afinal, o antigo aluno que dependia de todos para quase tudo, adquiriu uma autonomia digna de nota.

O despreparo de alguns professores em lidar com alunos com necessidades especiais não é mais problema para Alexandre, pois ele é o primeiro a ajudar na conscientização de todos os sujeitos envolvidos no processo de ensino aprendizagem, sejam estes professores, alunos, auxiliares administrativos, a não apresentarem atitudes paternalistas, nem excludentes, mas sim respeito para que as atividades do dia a dia sejam planejadas e executadas por todos e para todos, sem nenhum tipo de diferenciação.

\subsection{Concluindo o relato, mas não finalizando a história}

A história aqui relatada não será finalizada, tendo em vista que o protagonista deste relato e motivo primeiro do meu interesse sobre a problemática que envolve educação especial, tecnologias e ensino superior, ainda tem muito a aprender e a ensinar em sua caminhada tanto no UNESC como em outras atividades. 
Por conta disso, a conclusão que pode ser tirada do que aconteceu até o presente momento é que os alunos com necessidades educacionais especiais, muitas vezes encobertos por véus de indiferença ou estereotipados com nossos preconceitos ou tendências à padronização de suas condutas, têm muito a oferecer, a desenvolver e trazer muitas contribuições a nossa sociedade. Exemplo disso é o trabalho de conclusão de curso que Alexandre está desenvolvendo, cujo tema é "Tecnologias da Informação e Comunicação específicas para pessoas cegas e com baixa visão: realidade ou (im)possibilidade". Motivo de grande orgulho para discentes, docentes e principalmente para meu sentimento de trabalho cumprido.

Os rumos têm mudado e as tecnologias estão contribuindo, em vários aspectos, para o desvelamento da população que durante muito tempo ficou esquecida dentro dos muros de escolas especiais.

As Tecnologias de Informação e Comunicação - TICs têm produzido mudanças na ampliação dos horizontes sociais dos alunos com necessidades especiais de nossa sociedade. Alexandre, meu aluno, é prova disso.

\section{Aspectos conclusivos}

Finalizo o relato com as reflexões de Santos (2000) que fala da existência de três mundos e da globalização. O primeiro, denominado de globalização como fábula. Nele, as ideologias, os conceitos e a repetição estão em função de legitimar tal globalização e é também nele que encontramos o mito da aldeia global. O segundo mundo seria o da globalização perversa, sobre a qual traz a análise das inúmeras, contínuas e crescentes desigualdades criadas pela globalização, que se alega integradora, em busca da igualdade. Esta cria a utópica cidadania universal para poucos e dissemina "males morais e sociais da esquecida maioria", mas: A mesma materialidade, atualmente utilizada para construir um mundo confuso e perverso, pode vir a ser uma condição da construção de um mundo mais humano (p. 174).

Dentro das concepções de Santos, acredito ser fundamental contribuir com os estudos que hoje buscam entender, melhorar ou transformar as consequências advindas das globalizações citadas pelo autor. Comungo da ideia e do desejo desse mundo que pode vir a ser e, por isso, apresento meu intento de, a partir da pesquisa sobre a educação especial e inclusiva no ensino superior, participar do processo que deve estar a serviço do homem nessa transição em marcha de um mundo perverso para uma globalização, efetivamente, para todos.

Concluo o estudo com a afirmativa de que vivenciar uma escola inclusiva, comprometida com a aprendizagem e o envolvimento de educandos e educadores, no fecundo exercício do saber, é sem dúvida um grande desafio, mas que as tecnologias de comunicação e informação, podem e devem ser utilizadas a favor do aluno com necessidades educacionais especiais, e eu, como professora e pesquisadora, sou prova real disso. 


\section{Referências}

ASSUMANN, Hugo. Reencantar a educação: rumo à sociedade aprendente. Petrópolis: Vozes, 1998.

BALL, Stepher. Education Reform. Londres: Open University Press, 1997.

BRASIL. Constituição (1988). Constituição da República Federativa do Brasil. Brasília: Senado Federal, 1988. Disponível em: <http://www.planalto.gov.br/ccivil_03/constituicao/constitui\%C3\%A7ao.htm>. Acesso em: 16 fev. 2013.

BRASIL. Declaração de Salamanca e linhas de ação sobre necessidades educativas especiais. Brasília: CORDE, 1994.

BRASIL. Lei de Diretrizes e Bases da Educação Nacional - Lei no 9394, de 20 de dezembro de 1996. Estabelece as diretrizes e bases da educação nacional. Brasília, DF, 1996.

BRASIL. Lei no 10. 098, de 19 de dezembro de 2000. Estabelece normas gerais e critérios básicos para a promoção da acessibilidade das pessoas portadoras de deficiência ou com mobilidade reduzida, e dá outras providências Disponível em: <http://www.planalto.gov. br/ccivil_03/LEIS/L10098.htm>. Acesso em: 22 dez. 2012.

BRASIL. Ministério da Educação. Diretrizes nacionais para a educação especial na Educação Básica. Secretaria de Educação Especial-MEC/SEESP, 2001.

BRASIL. Ministério da Educação. Documento subsidiário à política de inclusão. MEC/SEESP, 2005.

BRASIL. Ministério da Educação. Secretaria de Educação Especial. Projeto Escola Viva: garantindo o acesso e permanência de todos os alunos na escola - Alunos com necessidades educacionais especiais. Brasília: MEC/SEESP, 2000. Vol. 6.

BOGDAN, R. C.; BIKLEN, S. K. Investigação qualitativa em educação. Portugal: Porto Editora, 1994.

CONFORTO, Débora; SANTAROSA, Lucila M. C. Acessibilidade à Web: Internet para todos. Revista de Informática na Educação: Teoria, Prática, PGIE/UFRGS, 2002.

DUSCHATZKY, Silvia; SKLIAR, Carlos. Os nomes dos outros: reflexões sobre os usos escolares da diversidade. Educação e Realidade, Porto Alegre, v. 25, n. 2, jul.-dez. 2000.

FARIA, Danielle de Oliveira Cabral. Vagas reservadas no ensino superior: igualdade de oportunidades. In: NEME, Eliana Franco (Coord.). Ações afirmativas e inclusão social. Bauru: Edite, 2005.

GIL, Antonio Carlos. Como elaborar projetos de pesquisa. 5. ed. São Paulo: Atlas, 2010.

HALL, Calvin S.; GARDNER, Lindzey. A psicologia existencial. In: HALL, Calvin S.; GARDNER, Lindzey. Teorias da personalidade. São Paulo: EPU, 1984.

INSTITUTO FEDERAL DO ESPÍRITO SANTO. Normas para apresentação de trabalhos acadêmicos e científicos: documento impresso e/ou digital. 5. ed. rev. ampl. Vitória: Ifes, 2012.

MAANEN, John, van. Reclaiming qualitative methods for organizational research: a preface. In: Administrative Science Quarterly, v. 24, n. 4, Dec. 1979a. 
MANTOAN, Maria Tereza Égler (Org.). O desafio das diferenças nas escolas. 3. ed. Petrópolis: Vozes, 2011.

ONU. Declaração dos Direitos Humanos. Declaração Universal dos Direitos Humanos. Adotada e proclamada pela resolução 217 A (III) da Assembleia Geral das Nações Unidas em 10 de dezembro de 1948. Disponível em: <http://portal.mj.gov.br/sedh/ct/legis_intern/ ddh_bib_inter_universal.htm>. Acesso em: 22 dez. 2012.

SANTOS, Mônica Pereira dos. Por uma outra globalização: do pensamento único à consciência universal. São Paulo: Record, 2000. SANTOS, Mônica Pereira dos; PAULINO, Marcos Moreira (Org.). Inclusão em educação: culturas, políticas e práticas. São Paulo: Cortez, 2006.

THOMA, Adriana da Silva. A inclusão no ensino superior: “- ninguém foi preparado para trabalhar com esses alunos (...) isso exige certamente uma política especial...”. GT Educação Especial, n. 15. 29. Reunião Anual da Anped, Caxambu, MG, 15 a 18 de outubro de 2006. Disponível em: <www.anped.org.br>. Acesso em: 10 dez. 2012.

UNESCO. Declaração Mundial sobre Educação para Todos. Satisfação das necessidades básicas de aprendizagem, realizada de 5 a 9 de março de 1990 em Jomtien, Tailândia. Disponível em: <http://unesdoc.unesco.org/images/0008/000862/086291por.pdf>. Acesso em: 15 dez. 2012.

VALENTE José Armando (Org.). Liberando a mente: computadores na educação especial. Campinas: UNICAMP, 1991.

WARSCHAUER, Mark. Tecnologia e inclusão social: exclusão digital em debate. São Paulo: SENAC, 2006.

WUCHER, Gabi. Minorias: proteção internacional em prol da democracia. São Paulo: Juarez de Oliveira, 2000.

Endereço para correspondência:

Renata Domingos

Rua Luiz Falcheto, 681 - Trevisan

CEP 29950- 000 Jaguaré, ES, Brasil

E-mail: <renatadomin@gmail.com>

Recebido em: novembro/2013

Aceito em: maio/2014 